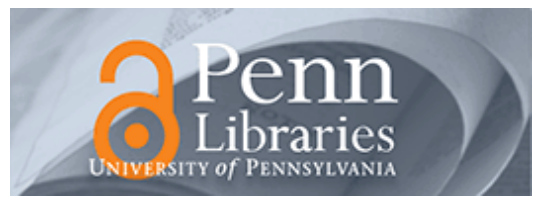

University of Pennsylvania ScholarlyCommons

$10-2006$

\title{
Discussion of an Economic Framework for Conservative Accounting and Bushman and Piotroski (2006)
}

Wayne R. Guay

University of Pennsylvania

Robert E. Verrecchia

University of Pennsylvania

Follow this and additional works at: https://repository.upenn.edu/accounting_papers

Part of the Accounting Commons, and the International Business Commons

\section{Recommended Citation}

Guay, W. R., \& Verrecchia, R. E. (2006). Discussion of an Economic Framework for Conservative Accounting and Bushman and Piotroski (2006). Journal of Accounting and Economics, 42 (1-2), 149-165. http://dx.doi.org/10.1016/j.jacceco.2006.03.003

This paper is posted at ScholarlyCommons. https://repository.upenn.edu/accounting_papers/38

For more information, please contact repository@pobox.upenn.edu. 


\title{
Discussion of an Economic Framework for Conservative Accounting and Bushman and Piotroski (2006)
}

\author{
Abstract \\ We offer an economic framework for generating predictions about the demand for conservative \\ accounting reports. We define conservatism as: More timely recognition of losses than gains as a result \\ of the costs and benefits of reporting verifiable information by managers and/or firms being asymmetric. \\ We also discuss Bushman and Piotroski's interpretation of the speeds of "good news recognition" and \\ "incremental bad news recognition" in "Basu-type" regressions as separate signals about accounting \\ conservatism. Finally, we suggest avenues for future research that seeks to investigate the links between \\ institutions and contracts, and between contracts and conservatism

\section{Keywords} \\ financial reporting, conservatism, timeliness of loss and gain recognition, international accounting, \\ political and legal institutions, contracting, compensation and incentives, debt contracts \\ Disciplines \\ Accounting | International Business
}




\title{
Discussion of an economic framework for conservative accounting and Bushman and Piotroski (2006) is
}

\author{
Wayne Guay*, Robert Verrecchia
}

The Wharton School, University of Pennsylvania, Philadelphia, PA 19104-6365, USA

Received 3 August 2005; received in revised form 8 February 2006; accepted 1 March 2006

\begin{abstract}
We offer an economic framework for generating predictions about the demand for conservative accounting reports. We define conservatism as: More timely recognition of losses than gains as a result of the costs and benefits of reporting verifiable information by managers and/or firms being asymmetric. We also discuss Bushman and Piotroski's interpretation of the speeds of "good news recognition" and "incremental bad news recognition" in "Basu-type" regressions as separate signals about accounting conservatism. Finally, we suggest avenues for future research that seeks to investigate the links between institutions and contracts, and between contracts and conservatism.
\end{abstract}

JEL classification: M41; M44; K22; G15; G38; O57

Keywords: Financial reporting; conservatism; timeliness of loss and gain recognition; international accounting; political and legal institutions; contracting; compensation and incentives; debt contracts

זrWe thank Sudipta Basu, Robert Bushman, John Core, Robert Holthausen, Christian Leuz, Ross Watts (the editor), and participants at the 2004 Journal of Accounting \& Economics Conference for comments and suggestions.

*Corresponding author. Tel.: +1 215-898-7775; fax: +1 215-573-2054.

E-mail address: guay@wharton.upenn.edu (W. Guay). 


\title{
Discussion of an economic framework for conservative accounting and Bushman and Piotroski (2006)
}

\author{
Wayne Guay and Robert Verrecchia ${ }^{1}$ \\ The Wharton School \\ University of Pennsylvania
}

\section{April 1, 2006}

\section{Introduction}

Bushman and Piotroski (2006) examine cross-country institutional determinants of accounting conservatism. In particular, the authors examine variation in accounting conservatism as a function of the legal/judicial system, securities laws, financial architecture, political economy, and tax regime. Accounting conservatism, defined by the authors to be the asymmetric recognition of economic gains and losses into earnings, is a widely documented feature of accounting reports. Knowledge of the nature and determinants of accounting conservatism is fundamental to understanding how and why financial reports are used in contracting, valuation, legal, and other institutional settings. By exploring these issues in a cross-country setting, Bushman and Piotroski (2006) advance this literature and our understanding of why and how accounting conservatism fits into the overall financial reporting system.

In this discussion, we focus on three issues. First, hypotheses about why asymmetric recognition of accounting gains and losses exists and varies across firms or countries do not appear to be developed from a common and accepted economic framework. Toward this end, in Section 3, we offer and briefly describe one such framework that we believe is useful in generating economic predictions about the demand for conservative accounting reports. We define conservatism as: More timely recognition of losses than gains resulting from asymmetric costs and benefits of reporting

\footnotetext{
${ }^{1}$ We thank Sudipta Basu, Robert Bushman, John Core, Robert Holthausen, Christian Leuz, Ross Watts, and participants at the 2004 Journal of Accounting \& Economics Conference for comments and suggestions.
} 
verifiable information by managers and/or firms with incentives to distort firm performance. A key takeaway from this framework is that arguments supporting the efficiency of conservative accounting need not emphasize the merits of timely recognition of losses, as these are obvious. Instead, arguments must articulate the merits of less timely recognition of gains. In other words, under an assumption that timely recognition of information is a desirable property of accounting reports, what are the costs and benefits that make accounting reports more efficient when recognition of economic gains is delayed relative to the recognition of economic losses?

Second, we discuss Bushman and Piotroski's interpretation for "Basu-type" regressions of earnings on stock returns. We express concern, or at least caution, about interpreting the speeds of "good news recognition" and "incremental bad news recognition" as separate signals about accounting conservatism. We illustrate how their interpretation of good and bad news recognition is equivalent to a conservatism measure based on the relative sensitivities of bad news and news in general. Further, we discuss conditions under which the relative sensitivity is a problematic measure of conservative accounting systems that facilitate efficient contracting. The intuition for this inference problem stems from the fact that the relative sensitivity interpretation will tend to categorize countries with less timely recognition of news in earnings as being more conservative.

Finally, we discuss Bushman and Piotroski's use of legal, political and financial institutions as proxies for contracting settings that demand conservative accounting. Little empirical evidence exists on whether contracts are actually used to a greater or lesser extent in the presence of specific legal, political and financial institutions. Further, there is limited empirical evidence on whether specific contracting settings demand more or less conservative accounting. Although Bushman and Piotroski's results support predicted relations between institutions and conservatism overall, we note that their evidence is not conclusive on the validity of these two implicitly assumed links. We 
suggest avenues for future research that directly investigate the links between institutions and contracts, and between contracts and conservatism.

\section{Summary of existing explanations for conservatism}

Watts (2003a, p. 211) notes that, "Contracting explains three attributes of accounting measures: timeliness, verifiability, and asymmetric verifiability." Watts (2003a, p. 207) also states, "Conservatism is defined as the differential verifiability required for recognition of profits versus losses. Its extreme form is the traditional conservatism adage: 'anticipate no profit, but anticipate all losses."

There has been considerable debate over the merits and determinants of conservatism. Ball (2001) and Watts (2003a, 2003b) summarize arguments and evidence that support conservatism as part of an efficient contracting technology. Both authors begin by assuming there exist two types of accounting information about net asset value and future cash flows: i) easy-to-verify information and, ii) difficult-to-verify information. Easy-to-verify information might consist of shocks to operating cash flow, accounts receivable, inventory, accounts payable, etc. In general, easy-toverify information is incorporated into financial statements in a timely manner and there is little debate that the asymmetric recognition of this information is necessary or desirable.

Discussions about conservatism mostly revolve around the accounting treatment of difficultto-verify information, which might consist of shocks to the value of R\&D activities, treatment of goodwill, restructuring costs related to plant closings, benefits from a brand name, etc. Ball (2001) and Watts (2003a) consider several characteristics of difficult-to-verify information that drive the efficient level of asymmetric gain and loss recognition, including: 1) greater costs of incorporating difficult-to-verify information into financial statements vis-à-vis easy-to-verify information; 2) 
lower reliability of difficult-to-verify information vis-à-vis easy-to-verify information; 3) asymmetric usefulness of profits and losses to some users of financial statements (e.g., bondholders); and 4) managerial incentives to bias financial reports upwards in an attempt to extract excess compensation.

It is not difficult to see why timely incorporation of information, if it can be collected and verified cost effectively, would improve the usefulness of financial reports to investors and other contracting parties. Further, it is not difficult to see how difficult-to-verify information might, in some cases, be too unreliable or costly to incorporate into financial statements. Therefore, the crux of the debate about the merits of conservatism should revolve around the question of why, conditional on the decision to incorporate some difficult-to-verify information into accounting statements, economic gains are recognized in a less timely manner than economic losses. We perceive that much of the existing literature on conservatism is focused exclusively on why information about losses should be incorporated in financial statements in a timely manner, with little if any, research on why information about gains should be excluded from timely recognition in financial statements.

Based on our reading of the existing literature, we identify three key characteristics of conservative accounting: $\left.{ }^{2} 1\right)$ Compared to accounting reports without conservatism, conservative accounting reports induce a downward bias in reported net assets; 2) Conservative accounting reports contain less timely information about gains than about losses; and 3) Conservative accounting rules impose greater costs on managers who wish to manipulate net assets upward. Below we articulate what we believe is a more transparent framework for thinking about

\footnotetext{
${ }^{2}$ See Watts (2003b) for an excellent discussion of these three characteristics as well as other empirical findings on conservatism.
} 
conservative financial reports, while preserving the spirit of the arguments summarized by Ball (2001), Watts (2003a), and others.

\section{An economic framework for conservative accounting}

\subsection{Conservatism as asymmetric costs and benefits of reporting verifiable information}

The purpose of this section is twofold. Firstly, we suggest an interpretation of conservatism that comports well with the extant theory on asymmetric costs and benefits of reporting verifiable information when managers or firms have incentives to bias or distort results of operations in their profit reports. Specifically, we interpret a conservative financial reporting system as one that results from two economic objectives: 1) to make it costly for a manager to deviate from the firm's true, economic earnings in accounting reports, and 2) to maximize the net benefits of financial reports, in which reporting verifiable information is costly and some users of financial statements have an asymmetric demand for information about losses and gains. Secondly, we point out that asymmetric conventions are inefficient from an information perspective. Thus, for an asymmetric convention to be efficient overall, it must more than compensate for the cost of this informational inefficiency. Further, we note that some contracting-based conservatism hypotheses, such as the role of conservatism in monitoring managerial compensation, rely heavily on the informational efficiency of conservative accounting, and as such appeared flawed.

We illustrate our interpretation of conservatism through a simple example. We consider a one-period model, adapted from Fisher and Verrecchia (2000), in which the manager observes (true) economic earnings and then reports results of operations with perhaps an element of bias intended to obfuscate true earnings. To keep the example as transparent as possible, we assume that economic earnings are comprised of an easily verifiable profit component (e.g., current period cash 
flow) plus a more difficult-to-verify anticipated profit component (e.g., a restructuring charge or appreciation in the value of an intangible asset). We assume that the easily verifiable component is positive $\$ 50$ million (henceforth, $\mathrm{m}$ ) in all states of the world. We restrict the difficult-to-verify anticipated component to be negative $\$ 30 \mathrm{~m}$ in a bad year, $\$ 0$ in a typical year, and positive $\$ 30 \mathrm{~m}$ in a good year. Thus, economic earnings' outcomes are a profit of $\$ 20 \mathrm{~m}$ in a bad year, a profit of $\$ 50 \mathrm{~m}$ in a typical year, and a profit of $\$ 80 \mathrm{~m}$ in a good year. The ex ante, or unconditional, probability of each outcome is as follows: a profit of $\$ 20 \mathrm{~m}$ occurs $25 \%$ of the time; a profit of $\$ 50$ $\mathrm{m}$ occurs $50 \%$ of the time; and a profit of $\$ 80 \mathrm{~m}$ occurs $25 \%$ of the time. As an aside, the actual profit figures, and the likelihood of those figures, or, for that matter, a profit versus a loss, are not important to this illustration; we choose these amounts as a matter of convenience.

Now consider the nature of an equilibrium to a circumstance in which the manager reports profits to the market. As in Fisher and Verrecchia (2000), we assume that on average the manager has an incentive to bias reports upward so as to favorably enhance firm share price, and that the market has rational expectations about the manager's actions. Further, we assume that standard setters, auditors, regulators, etc., impose personal costs on managers that bias reports. Hence, the manager trades off benefits of bias as a device to favorably enhance firm share price in the presence of a market that anticipates and discounts the bias to some degree, against the personal cost to the manager of biasing reports. These assumptions are generally consistent with Watts' (2003a) view that an important role of conservatism is to constrain management's opportunistic financial reporting behavior.

In addition, we impose a stylized representation of an asymmetric accounting convention: losses in the difficult-to-verify anticipated profit component should be reported, but gains can never be reported. In the latter case, because the manager cannot report difficult-to-verify anticipated 
gains, total profit for our illustrative firm cannot exceed $\$ 50 \mathrm{~m}$. Thus, in conjunction with this asymmetric accounting convention, the manager may only report credibly two profit figures: $\$ 20 \mathrm{~m}$, which occurs $25 \%$ of the time, and $\$ 50 \mathrm{~m}$, which occurs $75 \%$ of the time. ${ }^{3}$

We illustrate our concept of an economic role for asymmetric accounting conventions by contrasting two polar cases for the costs borne by the manager when biasing reports. In the first case, there are no costs associated with the manager biasing reports. Here, the manager reports $\$ 50$ m $100 \%$ of the time. The manager cannot report difficult-to-verify gains, which implies that profit cannot exceed $\$ 50 \mathrm{~m}$. By the same token, if there are no costs associated with biasing reports, the manager circumvents the recognition of difficult-to-verify losses by deferring recognition until the losses manifest themselves as a reduction in cash flow (i.e., in the easy-to-verify component of profits). Thus, in the end the manager reports $\$ 50 \mathrm{~m}$ exclusively.

It should be clear that when there is no cost to biasing reports and the manager reports $\$ 50$ m exclusively, the earnings report contains no information. In Figure 1, the line A-0-A' depicts the relation between reported earnings and economic earnings (or equivalently, change in price or returns) for this cost structure. Specifically, the slope coefficient in a regression of reported earnings and returns is zero in bad, typical, and good years.

\section{Insert Figure 1 here}

The purpose of examining this first cost structure is to emphasize that it is not the asymmetry of conservative accounting conventions, per se, that leads to difficult-to-verify losses

\footnotetext{
${ }^{3}$ As an aside, our characterization of a conservative accounting convention is not intended to suggest that difficult-toverify gains never manifest themselves as income. Difficult-to-verify gains that are unrecognized in a given period will ultimately show up in future income when the gains become easy to verify profit. The single period nature of our example, in conjunction with a characterization of a conservative accounting system as one in which difficult-to-verify gains go unrecognized at the end of the period, is intended to proxy for the untimely recognition of gains.
} 
being reported, but rather the costs and benefits to the manager associated with his taking certain actions in conjunction with these conventions (see for example, Ball, Robin and $\mathrm{Wu}, 2003$ for additional discussion on this issue). In fact, in this extreme case where the manager bears no costs from biasing earnings, difficult-to-verify losses are never reported in a timely manner, and the earnings report is no more informative than if the accounting system simply required recognition of easy-to-verify information. Thus, the existence of conservative accounting conventions may only be rough proxies for the costs associated with biasing, manipulating, or circumventing difficult-toverify losses. This point highlights the importance of research designs such as Bushman and Piotroski's (2006) that explore variation in conservative accounting reports as a function of the potential costs and benefits to firms and managers from misreporting their financial performance (e.g., variation in the strength of the judicial system, public enforcement, private enforcement, etc.).

Now consider a second cost structure in which it is prohibitively costly for managers to bias reports. Here the manager reports $\$ 20 \mathrm{~m} 25 \%$ of the time and $\$ 50 \mathrm{~m} 75 \%$ of the time. As it is prohibitively costly to circumvent the recognition of difficult-to-verify losses, the manager reports them. At the same time, the conservative accounting convention prohibits reporting difficult-toverify gains, and so profit cannot exceed $\$ 50 \mathrm{~m}$.

In Figure 1, the line B-0 depicts the relation between reported earnings and returns in a bad year in this cost structure. Because it is prohibitively costly for the manager to circumvent losses, the market rationally interprets the manager's report of a profit of $\$ 20 \mathrm{~m}$ as a true economic profit of $\$ 20 \mathrm{~m}$ with certainty, and prices the firm's activities correspondingly: the market sets the price of the firm at $\$ 20 \mathrm{~m}$. This, in turn, implies that if one were to associate a "bad news" report with the market price of the firm, the association would be 1 (in an experiment over time or across firms, this is equivalent to an $\mathrm{R}^{2}$ of $100 \%$ ). Thus, there is no informational inefficiency for bad news. Because 
earnings are reported truthfully in bad years, there is a one-to-one mapping between reported earnings and returns, and the slope coefficient is one.

In Figure 1, the line 0-B' depicts the relation between reported earnings and returns in typical (i.e., \$0 in difficult-to-verify items) and good years (\$30 million in difficult-to-verify items). Because the conservative accounting system prevents difficult-to-verify gains from being recognized, the manager reports a profit of $\$ 50 \mathrm{~m}$ in both typical and good years. The market, in turn, rationally interprets an earnings report of $\$ 50 \mathrm{~m}$ as true profit of $\$ 50 \mathrm{~m}$ with probability $50 \% \div$ $(50 \%+25 \%)=2 / 3$, and a true profit of $\$ 80 \mathrm{~m}$ with probability $25 \% \div(50 \%+25 \%)=1 / 3$. Thus, the market rationally prices the firm's activities at $2 / 3 \times \$ 50 \mathrm{~m}+1 / 3 \times \$ 80 \mathrm{~m}=\$ 60 \mathrm{~m}$. This, in turn, implies that if one were to associate a "typical news" report of $\$ 50 \mathrm{~m}$ (which the conservative accounting convention forces the manager to make irrespective of whether true profits are $\$ 50 \mathrm{~m}$ or $\$ 80 \mathrm{~m}$ ) with the $\$ 60 \mathrm{~m}$ market price of the firm, the association would be $83 \%$ (in an experiment over time or across firms, this is equivalent to an $\mathrm{R}^{2}$ of $83 \%$ ).

Here, obviously, there is an information loss, or inefficiency, associated with a "typical news" report compared to a "bad news" report. As a result, there is a less than one-to-one mapping between reported earnings and returns, and the slope coefficient is less than one (i.e., a dollar of earnings translates into less than a dollar of returns). The line B-0-B' depicts the well-known asymmetry, or "kink," in the earnings-returns relation that has been widely documented across firms and countries.

These polar cases of no costs and prohibitive costs on managers who bias earnings reports illustrate our interpretation of the economic underpinnings of conservatism. When greater conservatism is interpreted as the imposition of greater costs associated with biasing reports, the benefit of an economic system gravitating toward a more conservative standard is clear: the 
information content of reports increases, price efficiency increases, and the expected bias in reports declines.

We caution, however, that although our interpretation of conservatism illustrates the greater informational efficiency of a reporting system that recognizes difficult-to-verify losses in a timely manner vis-à-vis a reporting system that suppresses this information, our analysis to this point does not provide justification for the asymmetric recognition of gains and losses. To see the efficiency of symmetric recognition of gains and losses, suppose that the asymmetric accounting conventions described above were abandoned. Specifically, consider an accounting system that requires the symmetric recognition of both difficult-to-verify losses and gains in conjunction with the continuation of an environment in which it is prohibitively costly for the manager to bias reports. In this scenario, the manager reports truthfully in all states: he reports profits of $\$ 20 \mathrm{~m}, \$ 50 \mathrm{~m}$, and $\$ 80$ $m$ wherever appropriate. Here, there is no informational inefficiency. In Figure 1, the straight line B-0-B" depicts the relation between reported earnings and returns in this symmetric cost structure. Because earnings are reported truthfully in bad, typical and good years, there is a one-to-one mapping between reported earnings and returns, and the slope coefficient is one.

The key point here is that an asymmetric accounting convention that reports bad news in a timely manner, but good news in an untimely manner, creates informational inefficiencies. ${ }^{4}$ Empirically, there is substantial evidence that asymmetric accounting conventions are pervasive around the world, and that they have been so for a long time, suggesting that such conventions have stood the test of time and serve a valuable purpose (see, for example, Basu, 1997). The key question is $w h y$ ? Two possibilities come to mind. Firstly, it may be that both difficult-to-verify gains and

\footnotetext{
${ }^{4}$ Holthausen and Watts (2001) note that informational efficiency is neither a necessary nor sufficient condition for accounting reports to be useful or efficient for contracting purposes. We do not argue that informational efficiency is the primary objective of accounting reports, but rather that the merit of asymmetric informational efficiency in accounting reports requires articulation of a contracting or other economic explanation.
} 
losses are valuable from an information perspective, but that difficult-to-verify losses are less costly to incorporate into earnings (e.g., due to lower data collection costs, auditing costs, or willingness of management to report truthfully). This explanation, however, seems unlikely. As noted by Leuz (2001), it is difficult to see why gains are more costly to include in financial reports than losses, and if anything, it seems likely that managers would be more willing, not less willing, to report good news in a timely manner (see, for example, Ball and Shivakumar, 2005). The second possibility is that difficult-to-verify losses and gains are both costly to incorporate into earnings, but that the costs and benefits of information about losses and gains is asymmetric for certain parties that contract with the firm over reported earnings (e.g., bondholders, board members, regulators, etc.). We turn now to a discussion of this potential contracting role of conservatism.

\subsection{Contracting efficiencies of asymmetric recognition of gains and losses}

A large literature, including Ball (2001) and Watts (2003a), supports the asymmetric recognition of gains and losses by arguing that certain contracts are optimally written over reported accounting numbers, and that the efficiency of these contracts is improved by implementing conservative accounting conventions. Bushman and Piotroski motivate their hypotheses using six explicit and implicit contracting settings that might influence the demand for accounting conservatism: 1) debt contracts, 2) litigation costs, 3) political costs to regulators, 4) taxes, 5) political economy, and 6) managerial compensation contracts. Our interpretation of these arguments is that they generally rely on some combination of four assumptions: i) managers can, and have incentives to, bias accounting reports; ii) it is costly to incorporate difficult-to-verify information about anticipated cash flows into earnings due to audit costs, compliance costs, etc.; iii) important users of financial statements, such as debtholders, have an asymmetric demand for timely 
information about bad news; and iv) contracts are written over reported accounting numbers and it is costly to write contracts that adjust reported accounting numbers.

We begin our discussion of conservatism hypotheses by addressing what we perceive to be a common misconception about assumption i) above that managers have incentives to bias accounting reports. Specifically, we reiterate the points made by researchers such as Basu (1997) and Ball and Shivakumar (2005), who note that the mere existence of bias in reported accounting numbers is unlikely to make asymmetric conventions more efficient in many contracting settings. Bias can be accommodated readily within many contracting settings by simply adjusting the parameters of the contract. For example, if bondholders have rational expectations about reporting bias, the parameters of the debt covenants can (and will) be set to obtain the desired probability of technical default. Similarly, if compensation committees have rational expectations about reporting bias, the parameters of compensation contracts can be set (e.g., by adjusting the multiplier on reported earnings) to obtain the desired expected compensation. An example of the latter can be found in Slezak and Goldman (2005); they demonstrate how efficient compensation contracts can be written to accommodate managers who bias accounting reports along the lines suggested by Fisher and Verrecchia (2000). Therefore, to motivate the bias-reducing aspects of conservative accounting conventions in these settings, one must articulate why contracting over GAAP-imposed biasreducing accounting requirements is more efficient than firm-specific or even setting-specific contracts that account for expected bias or make conditional adjustments over time. We note, however, that in some very rigid contracting settings in which it is extremely costly to account or adjust for expected bias, such as the legal or political arena, reporting bias may induce a demand for conservative accounting. We discuss this latter possibility in more detail below. 
One of the more straightforward contracting settings that could create a demand for conservative accounting is debt contracts. Debtholders are an example of an important user of financial statements who have an asymmetric demand for good and bad news about profitability. Although debtholders demand information about both gains and losses, the fixed claims of debtholders are generally more sensitive to bad news about profitability or the value of net assets than they are to good news. ${ }^{5}$ For example, holders of debt in a financially healthy firm might find some important bad news relevant to valuing their claims, but will find good news relatively less important in valuing their claims. Thus, debtholders have a relatively greater demand for bad news, and if firms fail to provide such information, debtholders will price protect and impose a higher cost of capital on the firm. And, under the assumption that difficult-to-verify information about anticipated profitability is costly to incorporate into financial statements, it may be more efficient (i.e., less costly) for firms to incorporate more of the difficult-to-verify bad news and less of the difficult-to-verify good news into financial statements in a timely manner (the difficult-to-verify good news will be recognized into financial statements when it is realized and becomes easy-toverify good news).

Note that this role of conservatism in debt contracting is distinct from the argument made by Ball (2001), Bushman and Piotroski (2006) and others that conservatism serves a useful role in reducing slack in debt covenants. Borrowers and lenders will consider the existing accounting system and expected level of bias in reported financial reports when setting debt covenants. Further, as noted by Leuz (2001), it is inefficient to set covenants that trigger too often or too infrequently.

\footnotetext{
${ }^{5}$ The exception to this general rule is when debtholders' claims are substantially out of the money, in which case the claims are likely to be more sensitive to good news. However, debtholders with out-of-the-money claims (e.g., firms in bankruptcy) are likely to have greater access to financial information about the firm than is available through publicly filed reports.
} 
As such, the parameters of the covenants are expected to be set so that slack is neither too little nor too great, regardless of whether the accounting system is more or less conservative.

The existence of political, litigation, and tax costs are three other commonly posited arguments to motivate conservative accounting. In the political cost case, it is argued that politicians (and, in turn, firms) face asymmetric costs associated with incorporating bad news versus good news into financial reports. For example, politicians may be susceptible to greater pressures from their constituents when bad news is not incorporated into financial statements than when good news is not incorporated. Similarly, managers and shareholders may be more vulnerable to lawsuits when bad news is not incorporated into financial statements than when good news is not incorporated. Under the assumptions that reported accounting numbers cannot be adjusted easily in political and legal contractual settings, and difficult-to-verify anticipated profits and losses are costly to incorporate into financial statements, again, it may be efficient to incorporate difficult-to-verify bad news into financial statements and ignore difficult-to-verify good news. Further, unlike the debt contract example described above, it seems plausible that accounting conventions that simply offset managers' tendency to bias upward reported accounting numbers could reduce political and litigation costs (e.g., accounting conventions that reduce net assets by an average of $10 \%$ for each firm). This effect occurs because parties in these contracting settings, such as political constituencies and court systems, may not readily make adjustments to counteract negative reporting bias. ${ }^{6}$

The authors' tax hypothesis is that tax reporting and financial reporting are linked, and so firms have an incentive to report conservatively to minimize the present value of their tax burden.

\footnotetext{
${ }^{6}$ For example, imagine two firms, one of which is widely known to systematically underreport earnings by $10 \%$ every period and the other which is widely known to systematically overreport earnings by $10 \%$ every period. Although such underreporting results in no loss of information to sophisticated parties that contract with these firm, one can envision that a jury might be more likely to find the overreporting firm guilty of misleading investors.
} 
On one hand, taxing authorities are expected to have rational expectations about this incentive and can adjust the tax rates and code to take it into consideration (e.g., the Internal Revenue Service routinely adjusts the tax code to crack down on various shelters). On the other hand, one can envision the possibility that politicians face pressures to enact high corporate tax rates, but recognizing that excessive taxes can stifle investment and growth, regulators allow firms to report downward biased (i.e., conservative) earnings.

Bushman and Piotroski also introduce to the conservative accounting literature an interesting political economy argument. They suggest governments may be of two types: 1) self-serving, which attempt to take over profitable businesses to extract value or, 2) benevolent, which intervene when firms are inefficient and performing poorly. Firms want to avoid government intervention and can have incentives to either manage net assets and/or earnings upward (i.e., less observed conservatism) or downward (i.e., more observed conservatism) depending upon the type of government. However, a potentially confounding issue with the political economy argument is that governments presumably understand both the incentives that managers have to avoid intervention and the nature of accounting conventions, and likely will back it out in making intervention decisions; that is, governments may have rational expectations). Further, governments can also generally exert influence over accounting policy, and can potentially require accounting conventions that help convince their constituents that firms are either inefficient or profitable, depending on the government's objective.

Finally, an interesting feature of all of the explanations for conservatism thus far is that managers have incentives to report conservatively even in the absence of conservative accounting rules. That is, given that both firms and their managers bear costs from paying a higher taxes or cost of capital, or attracting costly political attention or litigation, mandated conservative accounting 
rules should not be necessary to achieve conservative accounting reports. In other words, when there is no agency conflict between firms and their managers, the managers have clear incentives to bias reports upward or downward depending on the direction that minimizes costs to the firm. Therefore, although these explanations predict variation in observed conservative accounting reports across political, legal, and tax regimes, they do not necessarily predict variation in the degree of conservative accounting rules.

The authors' final contracting setting argues that managerial compensation arrangements are expected to be more efficient when compensation contracts are written over conservative accounting numbers. However, this argument seems problematic and does not fit well within the economic framework we summarized above. To explain this concern, we first note that because accrual accounting and cash accounting result in the same total earnings over time (subject to clean surplus and other standard assumptions) preferences over accounting systems for compensation contracting stem from managerial horizon issues. A large literature documents the existence of both underinvestment and overinvestment by managers with short horizons. For example, as Ball and Shivakumar (2005) note, if losses are not recognized in a timely manner in earnings, managers with short horizons may not discontinue poorly performing projects. There is a flip side however, as recognized by Leuz (2001) and Watts (2003a), which is clearly conveyed in the following excerpt from Watts (2003a):

Agency cost-reducing contracts include debt contracts between the firm and holders of the firm's debt, management compensation contracts, employment contracts, and cost-plus sales contracts. Contracting parties demand timely measures of performance and net asset values for compensation and debt contract purposes. Ceteris paribus, managerial performance measures in compensation contracts, such as earnings, are more effective when they are timely and reflect the effects of the managers' actions on firm value in the period in which the actions are taken. Timeliness avoids dysfunctional outcomes associated with managers' limited tenure with the firm, often referred to as the manager's limited horizon. For example, a manager may forgo positive net present value projects with near-term negative earnings 
because future earnings will reflect the benefits of the project after the manager has retired or left the firm (Watts, 2003a, pg. 211).

Thus, if gains are not recognized in a timely manner, managers with short horizons may forgo investing in positive NPV projects. ${ }^{7}$ Therefore, if we make the assumption that it is efficient to write compensation contracts over accounting earnings (as opposed to contracting over stock returns or other performance measures), it is not clear why or how a compensation contract would necessarily be more efficient by excluding timely information about economic gains. Further, as noted above, managers' incentives to bias reported accounting numbers upward does not provide an obvious motivation for conservative accounting conventions (e.g., see again, Slezak and Goldman, 2005). Managers have incentives to bias reported accounting numbers upward regardless of whether or not conservative accounting conventions exist. Therefore, regardless of whether conservative accounting conventions exist, the firm must set the parameters of a compensation contract such that the manager is expected to earn his reservation utility. And, as such, conservative accounting reports alter the optimal weights in the compensation contract but are unlikely to improve the efficiency of these contracts. As a result, we are unable to endorse managerial compensation contracts as a candidate driving the demand for conservative accounting.

Our views on how various contracting settings create a demand for three features of conservative accounting are summarized in Table 1. In the first column, we predict that only the political costs, litigation, tax and possibly political economy settings are reasonably expected to

\footnotetext{
${ }^{7}$ As an example of a setting where timely gain and loss information might be important, consider a recent study by Bushman, Piotroski, and Smith (2005), who examine in a global setting the speed with which managers increase or decrease investment flows in response to improved or deteriorating investment opportunities, respectively. The focus of the authors' analysis is whether managers decrease investment flows in response to deteriorating investment opportunities more quickly when accounting information about losses is more timely. However, the authors' descriptive statistics indicate that the speed with which managers increase investment flows in response to improved investment opportunities varies as much across countries as the speed with which managers decrease investment flows in response to deteriorating investment opportunities. This comparison suggests that providing incentives for managers to take positive NPV projects may well be equally as important as providing managers with incentives to shut down negative NPV projects.
} 
create demand for a downward bias in earnings or net assets. We predict that increasing the marginal costs of manipulating difficult-to-verify information about both gains and losses is expected to lower contracting costs in all settings. Finally, we predict that the asymmetric recognition of difficult-to-verify losses and gains is potentially cost reducing only in the debt, litigation and political costs settings. However, note that our predictions do not consider the costs of implementing and enforcing accounting conventions or policies, and so we can only make statements about motivations for conservative accounting, not about the optimal level of conservatism, or truthful reporting in general.

\section{Interpretation of "good news sensitivity" and "incremental bad news sensitivity"}

In this section, we discuss Bushman and Piotroski's interpretation of their "Basu-type" regressions of earnings on stock returns. We illustrate potential inference problems stemming from an interpretation of conservatism based on the sensitivity of bad news relative to the sensitivity of news in general. In particular, we discuss conditions under which such an interpretation is unlikely to be consistent with the economic contracting theories of conservatism described above in Section 3. Our skepticism stems from the fact that the relative sensitivity interpretation will tend to categorize countries with less timely recognition of news in earnings as being more conservative.

Consistent with a large prior literature, Bushman and Piotroski define conservatism as the asymmetric recognition of economic gains and losses into earnings. To detect variation in conservatism across institutional structures, they develop a regression framework initiated by Basu (1997) and employed for cross-country comparisons by Ball, Kothari and Robin (2000) and Ball, Robin and $\mathrm{Wu}$ (2003). The Basu-type regression is illustrated by Bushman and Piotroski in their Equation (1): 


$$
\mathrm{NI}=\beta_{0}+\beta_{1} \mathrm{NEG}+\beta_{2} \mathrm{RET}+\beta_{3} \mathrm{NEG} * \mathrm{RET}+\varepsilon
$$

In this regression, "NI" is net income, "RET" is stock returns and is the proxy for news, and "NEG" is a dummy variable that equals one for negative returns and zero otherwise. In the most common interpretation of this regression, $\beta_{2}$ tells us how news, in general, is reflected in NI, where a larger coefficient indicates that earnings exhibits a greater response for a given amount of news in returns. $\beta_{3}$ tells us whether this mapping is incrementally different for bad news. When $\beta_{3}>0$, bad news is reflected in NI more quickly than good news, and accounting is considered to be conservative. We refer to this interpretation as the "incremental sensitivity" interpretation. Note that although $\beta_{2}$ is sometimes interpreted as "good news" sensitivity, this labeling is misleading because other things equal, when $\beta_{2}$ is smaller, both good news and bad news are less timely. Bushman and Piotroski follow Ball et al. (2000) and Ball et al. (2003) and explore cross-country differences in conservatism by testing whether the coefficients $\beta_{2}$ and $\beta_{3}$ vary with country-specific institutional characteristics.

In contrast to the incremental sensitivity interpretation described above, Bushman and Piotroski use an alternative interpretation of conservatism that considers countries to be more conservative if either $\beta_{3}$ is higher or $\beta_{2}$ is lower. Although not described explicitly as such by the authors, this interpretation is similar to a measure of the relative sensitivity of bad news to news in general as used in Pope and Walker (1999), Givoly and Hayn (2000), and Francis, LaFond, Olsson, and Schipper (2004). Intuitively, Bushman and Piotroski consider greater values of the following ratio of bad news sensitivity to general news sensitivity as indicating greater conservatism:

$$
\text { Greater }\left(\beta_{3}+\beta_{2}\right) / \beta_{2} \Rightarrow \text { Greater conservatism }
$$

Thus, Bushman and Piotroski consider a country to be more conservative either when bad news is incrementally timelier, i.e., $\beta_{3}$ is higher, or when news in general is less timely, i.e., $\beta_{2}$ is smaller. 
Bushman and Piotroski do not formally compute or statistically test for differences in this ratio, but instead look for differences across countries in $\beta_{2}$ and differences in $\beta_{3}$ as separate signals about the degree of conservatism.

Our main point in this subsection is to express caution regarding Bushman and Piotroski's interpretation of less timely news in general as evidence of greater conservatism. As described in Section 3 above, conservatism is hypothesized to facilitate contracting efficiency in various settings. In light of this role for conservatism, a problem with the relative sensitivity interpretation is that when two countries have accounting systems with similar incremental timeliness of bad news (i.e., similar $\beta_{3}$ ), the country with less timely recognition of news in general (i.e., smaller $\beta_{2}$ ) will be considered more conservative. It seems difficult to argue that, when two countries have similar incremental timeliness of bad news, the country with less timely recognition of news in general has an accounting system that facilitates greater contracting efficiency. Stated another way, for a given amount of incremental timeliness of bad news, the relative sensitivity measure will tend to favor firms or countries with untimely recognition of news in general as being more conservative and, therefore, as producing accounting reports that are more efficient for contracting purposes.

As a case in point, consider Bushman and Piotroski's Table 5 that examines the relation between conservatism and the strength of securities laws, as measured by strong public and private enforcement. In every specification tabulated, the incremental sensitivity of earnings to bad news is not significantly different across countries with different public and private enforcement. Thus, the incremental sensitivity interpretation of Table 5 is that there is no evidence that public enforcement or private enforcement is associated with conservative accounting. At the same time, however, the authors find lower sensitivity of news in general for countries with strong public enforcement. Their interpretation of this result is that strong public enforcement exhibits greater "relative sensitivity" 
and therefore greater conservatism. However, as noted above, it is difficult to see why, holding incremental bad news sensitivity constant, contracting efficiency is facilitated by less timely recognition of news in general in countries with strong public enforcement. Conversely, it is difficult to see why, holding incremental bad news sensitivity constant, countries with weak public enforcement have lower contracting efficiency simply because news in general is recognized in a timelier manner. To the contrary, one might reasonably argue that more timely general news recognition and equally timely incremental bad news recognition suggests a more, not less, useful accounting system for contracting.

Although we question the consistency of the relative sensitivity interpretation of conservatism with the economic hypotheses discussed in Section 3, we note that the incremental sensitivity interpretation is not without its own problems with respect to drawing inferences about an accounting system that improves contracting efficiency through conservatism. ${ }^{8}$ Specifically, the incremental sensitivity interpretation will conclude that two countries are equally conservative if they have similar incremental bad news sensitivities, i.e., similar $\beta_{3}$, but different general news sensitivities, i.e., different $\beta_{2}$. As with the relative sensitivity interpretation, one can argue that holding incremental timeliness of bad news constant, a country with more timely news in general has the accounting system that facilitates more efficient contracting. The incremental sensitivity interpretation fails to consider this variation in general news sensitivity.

Consistent with our discussion in Section 3 above, a key point with respect to both the relative and incremental sensitivity interpretations is that timelier recognition of news in general (or more specifically gains) does not imply an accounting system that is less efficient for contacting

\footnotetext{
${ }^{8}$ Pope and Walker (1999) and Basu (1999) discuss econometric strengths and weaknesses of the incremental and relative sensitivity interpretations.
} 
purposes. However, given that both interpretations have inference issues with respect to the role of timely recognition of gains, we believe that this is an important area for future research.

\section{Future research: Testing the links between institutions and accounting-based contracts, and between accounting-based contracts and conservatism}

Our final discussion point addresses avenues for future research on direct links between institutions and accounting-based contracts, and between accounting-based contracts and conservatism. The primary tests conducted by Bushman and Piotroski (Tables 4 through 6) are joint tests of the link between institutions and accounting-based contracts, and the link between accounting-based contracts and conservatism. Specifically, their research design examines the following link,

Institutions $\Rightarrow$ Prevalence of conservatism

as a joint test of the following two links,

Institutions $\Rightarrow$ Use of accounting-based contracts $\Rightarrow$ Demand for conservatism

To illustrate these links, consider the hypotheses and tests of a relation between the strength of the legal/judicial regime and accounting conservatism. The authors describe their predictions as follows: "If stronger legal/ judicial regimes lead to a more prominent role for the use of accounting numbers in formal contracts, firms in countries with stronger legal/ judicial regimes may respond to a higher 'contracting' demand for conservative reporting (Bushman and Piotroski, 2006, Section 2.2)." Thus, to motivate the first of the two links, the authors predict that strong legal / judicial regimes provide an enforcement mechanism that facilitates the use of accounting-based contracts. Similarly, the authors predict that strong securities laws will lower contracting costs, thereby increasing the use of accounting numbers in contracts. To motivate the second link, the authors predict that greater use of accounting numbers in contracts, in turn, creates a demand for verifiable 
and conservative accounting information. In Tables 4 and 5, the authors document evidence consistent with the predicted positive relation between the strength of both the legal / judicial regime and securities laws and accounting conservatism.

However, it is interesting to consider whether the two intermediate relations that link the authors' joint hypotheses actually hold across countries. To illustrate the importance of these intermediate links, consider the authors' predictions that stronger legal / judicial regimes and securities laws allow a more prominent role for contracts that use accounting numbers. As two proxies for the prominence of accounting-based contracts in their sample countries, the authors offer measures of the extent of private debt financing (as a fraction of country equity capitalization) and ownership concentration in the economy. The authors predict that accounting-based contracts are more prevalent in high private debt countries and where equity is more widely held. Examining Table 3 Panel B, we note that these proxies for accounting-based contracts do not always correlate with the strength of the legal /judicial regime or securities laws as predicted. On one hand, as predicted, private debt financing is more prevalent in strong judicial regimes $($ correlation $=+0.30)$. On the other hand, contrary to predictions, private debt financing is less prevalent in countries with strong securities laws (correlation $=-0.35)$.

One possible reason for these mixed correlations is that a strong legal / judicial regime might facilitate both less costly private debt financing and less costly equity financing, making the relation between the legal / judicial regime and the ratio of debt-to-equity financing difficult to predict. Another possibility is that the authors' proxies for the legal / judicial regime or the prevalence of accounting-based contracts are noisy. For example, widely-held equity and private debt financing may not be universally associated with greater accounting-based contracts. On the other hand, if widely-held equity and private debt financing are indeed good proxies for accounting-based 
contracts, then these variables may well be more direct proxies for the strength of the judicial /legal regime and securities laws than the authors' proxies for these institutional features. This argument follows from the expectation that if contracts are widely used by firms and investors in a country, this is prima facie evidence that an enforcement mechanism exists for these contracts. Given that links such as these are critical to our understanding of how institutions influence accounting reports, we believe the literature would benefit from more direct investigation of how institutions influence the use of accounting-based contracts.

The second link illustrated above, that greater prevalence of accounting-based contracts implies greater demand for conservatism, is also critical to the authors' joint hypotheses. In Tables 4 through 6, the authors simply assume this second link exists. However, in Table 7, the authors examine the interactive effect of proxies for accounting-based contracts on the relation between the strength of the legal / judicial regime and conservatism. For example, they ask whether countries with more private debt financing and less concentrated ownership exhibit a stronger relation between the legal / judicial regime and conservatism. However, if private debt financing and ownership concentration are good proxies for the use of contracts, then it becomes interesting to examine the main effect relation between conservatism and both private debt financing and ownership concentration as a more direct test of the second link described above. These main effect relations, as reflected by the coefficients $\beta_{11}$ and $\beta_{16}$ in Table 7 , are both interesting and puzzling. Specifically, it appears that accounting reports are actually somewhat less conservative in countries with greater private debt financing and less concentrated ownership (although we note the fact that private debt financing and ownership concentration are correlated makes it difficult to determine whether this is, in effect, one puzzling finding or two). 
As one possible explanation for this puzzling finding, consider the fact that accounting information is used not only for contracting purposes, but also for other purposes, such as equity valuation. Further, although countries with less concentrated equity ownership might use accounting information more extensively in contracts, the prevalence of widely-held equity in these countries is also likely to increase demand for accounting information that is useful for valuation purposes. And, as described in Section 3, asymmetric accounting systems that constrain the ability of managers to report information about gains are not expected to be the most efficient for equity valuation. Again, given the importance of understanding whether and how conservatism is influenced by the demand for accounting-based contracts, we believe the literature would benefit from a more complete investigation of the direct link between accounting conservatism and the prevalence of contracts that employ financial accounting numbers.

\section{Concluding remarks}

Bushman and Piotroski (2006) provide an interesting and informative examination of crosscountry institutional determinants of accounting conservatism. In this respect, the authors develop predictions and provide supportive empirical evidence on how accounting conservatism varies with countries' legal/judicial system, securities laws, financial architecture, political economy, and tax regime.

Preparatory to analyzing Bushman and Piotroski, in this discussion we attempt to integrate the extant literature on conservatism into a common and accepted economic framework. Toward that goal, we argue that conservatism can be interpreted as more timely recognition of losses than gains resulting from asymmetric costs and benefits of reporting verifiable information by managers and/or firms with incentives to distort firm performance. We emphasize that accounting conventions 
that report bad news in a timely manner but good news in an untimely manner creates informational inefficiencies. Thus, for an asymmetric accounting convention to represent an efficient reporting system, contracting or other benefits must exist that more than compensate for these informational inefficiencies. Using this framework, we discuss and critique the contracting settings that have been offered by Bushman and Piotroski and others to support predictions about variation in conservatism across countries. In discussing these contracting settings, we stress the importance of considering both the benefits and costs of asymmetric recognition of gains and losses. We also note that some commonly accepted contracting explanations (e.g., conservatism's role in compensation contracts) appear to rely inappropriately on conservatism improving the informational efficiency of contracts.

Insofar as Bushman and Piotroski explore variation in conservative accounting reports as a function of the potential costs and benefits to firms and managers from misreporting their financial performance, arguably their research design anticipates our perspective. Nonetheless, in the implementation of their Basu-type regressions of earnings on returns, we note that Bushman and Piotroski rely on an interpretation of conservatism that is based on the "relative sensitivity" of bad news to news in general. We express concern about this interpretation by illustrating how, other things equal, it is expected to view countries with less timely recognition of news in general as being more conservative. As our final point, we suggest that the literature on conservatism would benefit from additional research examining the direct links between institutions and the use of accounting-based contracts, and between the use of accounting-based contracts and the degree of conservatism in observed accounting reports. 


\section{References}

Ball, R., 2001. Infrastructure requirements for an economically efficient system of public financial reporting and disclosure. Brookings-Wharton Papers on Financial Services, R. Litan and R. Herring (eds), Washington: Brookings Institution Press, 127-169.

Ball, R., Kothari, S.P., Robin, A., 2000. The effect of international institutional factors on properties of accounting earnings. Journal of Accounting \& Economics 29, 1-51.

Ball, R., Robin, A., Wu, J., 2003. Incentives vs. standards: Properties of accounting income in four East Asian Countries. Journal of Accounting \& Economics 36, 235-270.

Ball, R., Shivakumar, L., 2005. Earnings quality in U.K. private firms: comparative loss recognition timeliness. Journal of Accounting \& Economics 39, 83-128.

Basu, S., 1997. The conservatism principle and the asymmetric timeliness of earnings. Journal of Accounting \& Economics 24, 3-37.

Bushman, R., Piotroski, J., 2006. Financial reporting incentives for conservative accounting: The influence of legal and political institutions. Journal of Accounting \& Economics, (this issue).

Bushman, R., Piotroski, J., Smith, A., 2005. Capital allocation and timely accounting recognition of economic losses: International evidence. Working paper, University of Chicago.

Fischer, P., Verrecchia, R., 2000. Reporting bias. The Accounting Review 75, 229-245.

Francis, J., LaFond, R., Olsson, P., Schipper, K., 2004. Costs of equity and earnings attributes. The Accounting Review 79, 967-1010.

Givoly, D., Hayn, C., 2000. The changing time-series properties of earnings, cash flows, and accruals: Has financial reporting become more conservative?. Journal of Accounting \& Economics 29, 287-320.

Holthausen, R., Watts, R., 2001. The relevance of the value relevance literature for financial accounting standard setting. Journal of Accounting \& Economics 31, 3-75.

Leuz, C., 2001, Comment on infrastructure requirements for an economically efficient system of public financial reporting and disclosure. Brookings-Wharton Papers on Financial Services, R. Litan and R. Herring (eds), Washington: Brookings Institution Press, 170-177.

Pope, P., Walker, M., 1999. International differences in the timeliness, conservatism, and classification of earnings. Journal of Accounting Research 37 (Supplement), 53-87.

Slezak, S., Goldman, E., 2005. An equilibrium model of incentive contracts in the presence of income manipulation. Journal of Financial Economics, forthcoming. 
Watts, R., 2003a. Conservatism in accounting part I: Explanations and implications. Accounting Horizons 17, 207-221.

Watts, R., 2003b. Conservatism in accounting part II: Evidence and Research Opportunities. Accounting Horizons 17, 287-301. 


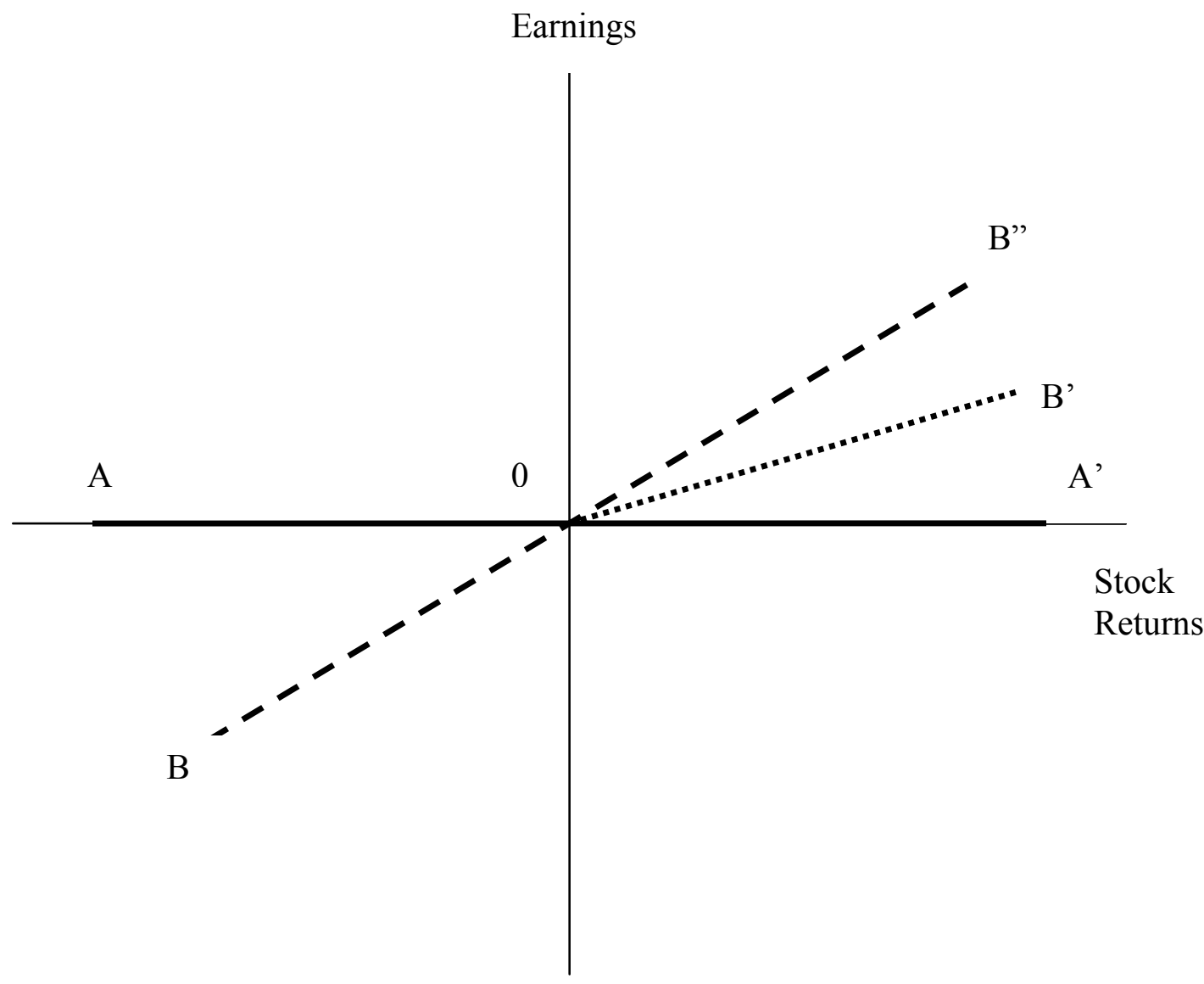

Fig. 1. Illustration of the relation between reported earnings and stock returns. The line A-0-A' depicts the relation between reported earnings and returns when there is no cost to managers from biasing reports. The line B-0-B' depicts the relation between reported earnings and returns when it is prohibitively costly for managers to bias reports, but where a conservative accounting system prevents difficult-to-verify gains from being recognized in earnings. The line B-0-B" depicts the relation between reported earnings and returns when it is prohibitively costly for managers to bias reports, but where the accounting system is symmetric and allows difficult to verify gains and losses to be recognized in earnings. 
Table 1

The relation between contracting costs and three features of conservative accounting

\begin{tabular}{|c|c|c|c|}
\hline & \multicolumn{3}{|c|}{ Feature of conservative accounting } \\
\hline $\begin{array}{l}\text { Contracting } \\
\text { Setting }\end{array}$ & $\begin{array}{l}\text { Would imposing a downward } \\
\text { bias in earnings or net assets } \\
\text { lower contracting costs? }\end{array}$ & $\begin{array}{l}\text { Would increasing the marginal cost of } \\
\text { manipulating difficult-to-verify gains } \\
\text { and losses lower contracting costs? }\end{array}$ & $\begin{array}{l}\text { Would excluding difficult-to-verify } \\
\text { information about gains lower } \\
\text { contracting costs? }\end{array}$ \\
\hline Debt contracts & Unlikely & Likely & Possibly \\
\hline Political costs & Possibly & Likely & Possibly \\
\hline Litigation & Possibly & Likely & Possibly \\
\hline Taxes & Possibly & Likely & Unlikely \\
\hline $\begin{array}{l}\text { Political } \\
\text { Economy }\end{array}$ & Indeterminate & Likely & Unlikely \\
\hline $\begin{array}{l}\text { Compensation } \\
\text { contracts }\end{array}$ & Unlikely & Likely & Unlikely \\
\hline
\end{tabular}

